\title{
IMPORTANCE OF THE LIPID PEROXIDATION BIOMARKERS AND METHODOLOGICAL ASPECTS FOR MALONDIALDEHYDE QUANTIFICATION
}

\author{
Denise Grotto, Lucas Santa Maria, Juliana Valentini, Clóvis Paniz, Gabriela Schmitt e Solange Cristina Garcia* \\ Departamento de Análises Cínicas e Toxicológicas, Universidade Federal de Santa Maria, CP 5061, 97110-970 Santa Maria - RS, \\ Brasil
}

Valdeci Juarez Pomblum

Departamento de Clínica Médica, Universidade Federal de Santa Maria, 97110-970 Santa Maria - RS, Brasil

João Batista T. Rocha

Departamento de Bioquímica Toxicológica, Universidade Federal de Santa Maria, 97110-970 Santa Maria - RS, Brasil

Marcelo Farina

Departamento de Bioquímica, Universidade Federal de Santa Catarina, 88040-900 Florianópolis - SC, Brasil

Recebido em 16/2/07; aceito em 7/3/08; publicado na web em 31/10/08

\begin{abstract}
Free radicals induce lipid peroxidation, playing an important role in pathological processes. The injury mediated by free radicals can be measured by conjugated dienes, malondialdehyde, 4-hydroxynonenal, and others. However, malondialdehyde has been pointed out as the main product to evaluate lipid peroxidation. Most assays determine malondialdehyde by its reaction with thiobarbituric acid, which can be measured by indirect (spectrometry) and direct methodologies (chromatography). Though there is some controversy among the methodologies, the selective HPLC-based assays provide a more reliable lipid peroxidation measure. This review describes significant aspects about MDA determination, its importance in pathologies and biological samples treatment.
\end{abstract}

Keywords: oxidative stress; MDA; methodologies.

\section{INTRODUCTION}

Cells continuously produce free radicals and reactive oxygen species (ROS) as part of their metabolic processes. ${ }^{1}$ ROS can be produced by either breakage of covalent bond, addition of electrons to a molecule or removal of hydrogen by other radicals. They are generally highly reactive species and typically act as electrophilic species or oxidant agents. The most important radicals or pro-oxidant molecules involved in disease processes are superoxide $\left(\mathrm{O}_{2}{ }^{-}\right)$, hydroxyl radical $\left(\mathrm{OH}^{*}\right)$, hydrogen peroxide $\left(\mathrm{H}_{2} \mathrm{O}_{2}\right)$ and certain oxides of nitrogen, like nitric oxide (NO) and peroxynitrite $\left(\mathrm{ONOO}^{-}\right){ }^{2}$

The overproduction of reactive species results in oxidative stress. In other words, it can be a combination of an increased formation of oxygen-nitrogen derived radicals and reduced antioxidant capacity, causing an imbalance that might result in the attack of cellular components, especially lipids. It has been implicated in the pathogenesis of various diseases including diabetes, ${ }^{3}$ cancer, ${ }^{4}$ and atherosclerosis. ${ }^{3,5}$

Since it is complex measuring free radicals directly in vivo, it is necessary to carry out the quantification of cellular components which can react with these free radicals, such as proteins, ${ }^{6} \mathrm{DNA}^{7}$ and mainly lipids. ${ }^{8}$ Once lipid peroxides are unstable compounds, they tend to degrade rapidly in a variety of sub products. MDA is one of the most known secondary products of lipid peroxidation, and it can be used as a marker of cell membrane injury. ${ }^{9}$ Lipid peroxidation can also be assessed by measurement of conjugated dienes, ${ }^{10}$ ethane and pentane gases, ${ }^{11}$ isoprostanes ${ }^{12}$ and 4 -HNE. ${ }^{9}$ Another way to measure the oxidative damage is by protein ${ }^{13}$ and DNA modifications, ${ }^{7}$ but these markers many times can be formed by pathways other that from free radicals. Thus, MDA is far the most popular indicator of oxidative damage to cells and tissues.

Since the 1960s, several methods have been developed to assess

*e-mail: sgarpom@smail.ufsm.br
MDA, including quantitative methods using spectrophotometry or fluorimetric detection, high performance liquid chromatography (HPLC), gas chromatography and immunological techniques. ${ }^{14,15}$

In this review, we will discuss the validity, advantages and disadvantages of using MDA as an indicator of oxidative stress, and the methods for its determination, including determination by HPLC with different detectors, colorimetric techniques, which have been widely criticized, and gas chromatography techniques.

\section{LIPID PEROXIDATION AND MDA}

Lipid peroxidation is a free-radical-mediated chain of reactions that, once initiated, results in an oxidative deterioration of polyunsaturated lipids. The most common targets are components of biological membranes. When propagated in biological membranes, these reactions can be initiated or enhanced by a number of toxic products, including endoperoxides and aldehydes. ${ }^{16}$

MDA is a three-carbon, low-molecular weight aldehyde that can be produced by different mechanisms. Dahle et al. ${ }^{17}$ postulated a mechanism of MDA formation based on the fact that only peroxides that possessed $\alpha$ or $\beta$ unsaturations to the peroxide group could be capable of undergoing cyclization to finally form MDA.

A MDA formation route is described in Figure 1. The target of reactive species is the carbon-carbon double bond of polyunsaturated fatty acids (I). This double bond weakens the carbon-hydrogen bond, allowing easy abstraction of the hydrogen by a free radical. Then, a free radical can abstract the hydrogen atom and a lipid free radical is formed (II), which suffers oxidation generating a peroxyl radical (III). The peroxyl radical can react with other polyunsaturated fatty acids, abstracting an electron and producing a lipid hydroperoxide (IV) and another lipid free radical. This process can be propagated continually in a chain reaction. ${ }^{2,18}$ The lipid hydroperoxide is unstable and its fragmentation yields products such as malondialdehyde (V) and 4-hydroxy-2-nonenal. 


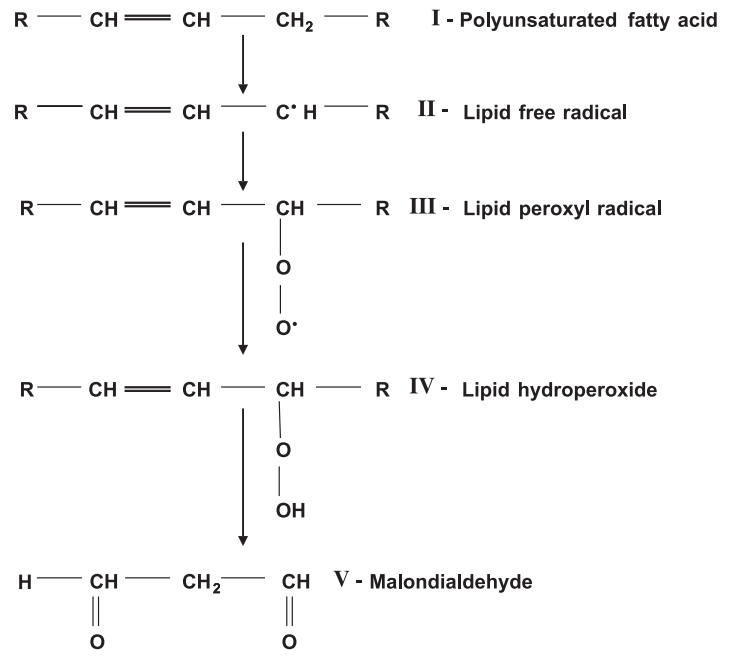

Figure 1. Schematic steps of MDA formation from polyunsaturated fatty acids

Studies have showed that a considerable amount of MDA can potentially be derived from the following sources: fatty acids with less than three double bonds. ${ }^{19,20}$ In this case, MDA production is partially due to the secondary oxidation of primary carbonyl compounds; ${ }^{18,21}$ endoperoxides involved in the synthesis of prostaglandins; ${ }^{19}$ irondependent oxidative degradation of amino acids, carbohydrates, pentoses and hexoses and from free radical products produced by gamma irradiation. ${ }^{22}$

In physiological conditions, oxy-radicals are part of the normal regulatory course of the organism and the cellular redox state is closely controlled by antioxidants. When the levels of free radicals increase and both the enzymatic systems and low molecular antioxidants are not sufficient to protect the organism, these radicals attack membranes and cells. This process is particularly important in the vascular system, where they can damage the endothelium by peroxidation and initiate the atherosclerotic lesion. ${ }^{23}$

$\mathrm{NO}$ is known as a vascular smooth muscle tone controller, it inhibits platelet activation, modulates apoptosis and inflammatory cell aggregation and activation at low concentrations. On the other hand, NO can react with superoxide anion $\left(\mathrm{O}_{2}\right)$ to form peroxynitrite $\left(\mathrm{ONOO}^{-}\right)$, which is highly cytotoxic. The damage of the vascular endothelium is always followed by vasoconstriction, platelet aggregation and inflammatory cell adhesion, which lead to an increased production of $\mathrm{NO}$ and, consequently, $\mathrm{ONOO}^{-}$. Associated with other factors, the overproduction of $\mathrm{NO}$ is one of the most important issues involved in the development of lipid atherosclerotic plaques. ${ }^{23}$

In the last 20 years, MDA has been recognized as an important lipid peroxidation indicator, since subjects affected by several diseases have the MDA levels increased. . $^{3-5,24}$

The involvement of lipid peroxidation in cancer is a good example; cancer results from the accumulation of the multiple mutations in key growth regulatory genes. These genetic changes are a consequence of both the instability of DNA and DNA replication errors which result from exposure to exogenous genotoxins ${ }^{25,26}$ and reactive oxygen species. ${ }^{27} \mathrm{MDA}$ is a potentially important contributor to DNA damage and mutation that is produced endogenously via lipid peroxidation. Cirak et al. ${ }^{28}$ suggest that oxidative stress is increased in malignant brain tumors with higher levels of serum and tissue MDA when compared to healthy controls. Thus, MDA can be used as one of the markers for diagnosis and follow up malign tumors.

In diabetes, persistent hyperglycemia may cause high production of free radical attributed to protein glycation or glucose autooxidation. ${ }^{29}$ MDA levels were found higher in Type 2 diabetics than in healthy controls in a study carried out by Kesavulu et $a l .^{3}$ The research group also observed that diabetic patients with coronary heart disease had higher levels of MDA than those diabetics without this disease. It shows that cardiovascular diseases have also been related to free radical-mediated mechanisms and to lipid peroxidation, along with the fact that they are a major cause of mortality and morbidity in hemodialysis patients. Study reported by Scott et al. ${ }^{30}$ demonstrated that plasma MDA values were elevated in hemodialysis patients and higher in hemodialysis patients with cardiovascular complications.

Finally, MDA is increased in Alzheimer's disease. The central nervous system is vulnerable to lipid peroxidation owing to high brain oxygen consumption and also to its rich polyunsaturated fatty acid content; it is relatively deficient in antioxidant enzymes ${ }^{31}$ as well. Marchasson et al. ${ }^{32}$ found plasma MDA levels higher in Alzheimer's disease patients than in healthy controls.

In fact, MDA measurement is very important in pathological states, but it has also a large significance on the toxicological effects of pollutants such as metals, solvents and xenobiotics in humans and animals. MDA quantification has been widely used in studies involving the toxicity mechanism of several substances, as paraquat, ${ }^{33}$ carbon tetrachloride ${ }^{34}$ and metal exposition, as cadmium, ${ }^{35}$ aluminum. ${ }^{36}$ Moreover, the effects of a mixture containing substances from petroleum industry on the activity of enzymes and the biochemical parameters have been studied. ${ }^{37}$ However, the exact role played by lipid peroxidation on cellular toxicity has not yet been clearly identified whether lipid peroxidation is the cause or is a secondary out come of cellular injury. Thus, the elucidation of this question will have to wait additional experimental and clinical studies.

Besides MDA as an index of lipid peroxidation, 4-hydroxynonenal (4-HNE) has an important role in oxidative stress. 4-HNE is an aldehyde formed by peroxidation of $\omega-6$ fatty acid. ${ }^{9}$ Millimolar concentrations of 4-HNE take to depletion of glutathione, inhibition of DNA, RNA and protein synthesis and they are acutely cytotoxic., ${ }^{9,38}$ This aldehyde may be measured by highly specific and sensitive gas chromatography/mass spectrometry (GC/MS) methods, ${ }^{6}$ which are expensive and uncommon techniques in laboratories.

The peroxidation of unsaturated fatty acids is accompanied by the formation of conjugated dienes that reflect an early stage of oxidative stress. ${ }^{39}$ Further limitations of this technique are that production of dienes continues to occur ex vivo, and absorption of these compounds at $230-235 \mathrm{~nm}$ is not specific for lipid peroxidation products. ${ }^{10}$

A non-invasive measure of lipid peroxidation concerns the measurement of a group of volatile hydrocarbons, the alkanes, including ethane, pentane and isoprene ${ }^{11}$ that are formed by polyunsaturated fatty acids oxidation. The methodology used is GC, which, besides being expensive, has difficulty to separate pentane and isoprene, because of their similar boiling points. ${ }^{40}$ Additionally, hydrocarbon gases are produced by bacteria and are susceptible to varying rates of in vivo metabolism. ${ }^{41}$

Another measure that has been used to detect the extent of lipid peroxidation is F2-isoprostanes, isomers of prostaglandins produced by non-cyclooxygenase dependent peroxidation of arachidonic acid. ${ }^{42}$ Although isoprostanes are not a major product of lipid peroxidation, they can be easily detected by $\mathrm{GC} / \mathrm{MS},{ }^{43}$ however it is a timeconsuming and expensive technique.

Various reactive electrophilic compounds from lipid peroxidation, in particular MDA, have been showed to be mutagenic and genotoxic, ${ }^{4}$ which can lead to cancer formation. MDA can react with nucleic acid bases at physiological $\mathrm{pH}$ and forms adducts with deoxyguanosine $(\mathrm{dG})$, deoxyadenosine $(\mathrm{dA})$ and deoxycytidine $(\mathrm{dC}),{ }^{7}$ such as the pyrimido $[1,2 \alpha]$ purin- $10(3 \mathrm{H})$-one $\left(\mathrm{M}_{1} \mathrm{G}\right)$, the $\mathrm{N}^{6}$-(3-oxopropenyl) deoxy-adenosine $\left(\mathrm{M}_{1} \mathrm{~A}\right)$ and the $\mathrm{N}^{4}$-(3-oxopropenyl-deoxycytidine $\left(\mathrm{M}_{1} \mathrm{C}\right)$. These products can be measured by GC/MS, which is a spe- 
cific technique, and enzymatic assays. ${ }^{44}$ Another probable toxic action of MDA is its cross-linking with collagen, which may contribute to the stiffening of cardiovascular tissue. ${ }^{45}$

An increase in blood protein carbonyls has been reported in oxidative stress. When reactive oxygen and nitrogen species attack amino acids, lipids and carbohydrates, carbonyls groups are produced and measured by HPLC or immune assay techniques, ${ }^{44}$ however, these techniques have been criticized as being non-specific and unreliable. Besides, the protein carbonyls quantification did not reflect the lipid peroxidation, but the protein oxidation.

Although others biomarkers can be used to measure the lipid peroxidation, the MDA quantification in pathologies and toxicology is the most utilized, and different chemical methods have been described for its measurement. The techniques widely used are determination of MDA-TBA complex by indirect spectrophotometry or fluorimetry and by direct HPLC with different detectors. MDA molecule is small, polar and highly water-soluble, making it difficult to extract. It contains no eletrophore, chromophore or fluorophore that would enable detection at the requisite sensitivities for biological study, moreover MDA is relatively unstable. Therefore, analytical derivatization is a commonly employed solution to these difficulties and, chromatographic methodologies have been considered as a more specific measure than the widely used technique of determining thiobarbituric acid reactive substances.

\section{BIOLOGICAL SAMPLES}

\section{The choice of the sample for MDA determination}

The measurement of MDA values can be made in a variety of biological samples. The use of thiobarbituric acid reactive substances (TBARS) assay has been carried out in plasma,${ }^{30,46-51}$ serum,${ }^{52}$ different tissues, ${ }^{28,47,48,53}$ and occasionally in urine. ${ }^{54}$

Urinary MDA is excreted mainly in form of adducts with lysine and its $\mathrm{N}$-acetylated derivative, indicating an association with proteins. ${ }^{54}$ Therefore, urinalysis for aldehydic products of lipid peroxidation can be done, but this technique has not proved to be a reliable method to indicate the general state of oxidative stress. Urinary excretion of MDA is prejudiced by ingestion of lipids and exercises. ${ }^{54}$ Thus, as pointed out above, the quantification of MDA in urine has low clinical significance.

Tissues used in measurement of MDA, such as brain, liver, lung, kidney and heart, may be homogenized with phosphate-buffered saline and kept on ice. Brain is more sensitive to in vitro oxidation than other organs because of its higher contents of polyunsaturated fatty acids. ${ }^{48}$ In fact, the tissue auto-oxidation in vitro can be used to assess its susceptibility to oxidative stress. ${ }^{53,55}$

The evaluation of the lipid peroxidation in tissues is a good marker to measure the extent of the oxidative stress, but it is important to consider that these biological samples can only be used in experimental studies. Therefore, plasma sample is still the most used.

\section{Sample preparation and storage}

Once the most used biological sample is plasma, literature data indicate what type of anticoagulant can be used in MDA assay: sodium heparin, ${ }^{49,56}$ sodium citrate ${ }^{49}$ and tripotassium EDTA. ${ }^{46,49,51}$ EDTA seems to be preferable over citrate and heparin, because lowest plasma MDA levels are found, probably related to iron chelation by EDTA in the TBARS assay as well as its weak activity such as an antioxidant.$^{57}$ On the other hand, it is important to consider that EDTA can complex with iron ions, forming the Fe-EDTA complex, which can participate in the Fenton reaction, forming the $\mathrm{OH}^{\bullet}$ radical and overestimating the lipid peroxidation. ${ }^{58}$

Blood samples may be kept at $4-5^{\circ} \mathrm{C}$ until centrifugation ${ }^{49,50}$ to prevent transformation of MDA in other compound or its reaction with other cellular components, resulting in erroneous results.

Researches showed that samples were stable at $-20{ }^{\circ} \mathrm{C}$ for a month, and for periods longer than this, it is recommended to store the samples at $-80 /-85^{\circ} \mathrm{C} .49,56,59$

To prevent further formation of MDA during the assay, an antioxidant can be used; butylated hydroxy-toluene (BHT) is one of the most widely used compound. ${ }^{47,50,56,60}$ However, Karatas et al. ${ }^{52}$ did not find difference between the amounts of MDA-TBA adduct with and without BHT. On the other hand, a study by Pilz et al. ${ }^{61}$ demonstrated clearly that the reduced MDA levels are merely the effect of ethanol alone - probably by the protein precipitation - and not of the BHT, once the BHT is dissolved in ethanol or methanol. This effect was also observed in the work from Grotto et al. ${ }^{51}$ Using Ohkawa's method ${ }^{62}$ we observe that the presence of SDS reduces autoxidation of tissues during the preparation of the sample or during the heating step.

Usually, biological sample is mixed with an acid to precipitate proteins. It can be used different acids and concentrations: $0.66 \mathrm{~N}$ of $\mathrm{H}_{2} \mathrm{SO}_{4},{ }^{47} 0.1 \mathrm{M}$ of $\mathrm{HClO}_{4},{ }^{52} 0.44 \mathrm{M}, 1$ or $6 \%$ of (orto) phosphoric acid, ${ }^{49,51,56}$ respectively, $7.2 \%$ of TCA. ${ }^{56}$ After centrifugation, TBA is added to supernatant ${ }^{8}$ and the reaction is effectuated by heating around $95^{\circ} \mathrm{C}$ during $60 \mathrm{~min} .{ }^{62}$

\section{METHODS FOR MDA DETERMINATION}

\section{TBARS assay}

In 1968, Yagi et al. ${ }^{63}$ applied the reaction of TBA with MDA and linked chromogens to lipoperoxides in biomaterials; this reaction was carried out at $95{ }^{\circ} \mathrm{C}$, in acid conditions, resulting in the well-known method "thiobarbituric acid reactive substances" (TBARS). Its product can be detected by colorimetry $(532-535 \mathrm{~nm})$ or fluorimetry (excitation at $532 \mathrm{~nm}$ and emission at $553 \mathrm{~nm}$ ). ${ }^{64}$

Formation of MDA-TBA adduct occurs by a nucleophilic attack involving carbon- 5 of TBA and carbon- 1 of MDA, followed by dehydration and similar reaction with a second molecule of TBA (Figure 2), producing a red pigment. ${ }^{65}$ The intensity of the pink pigment formed from MDA-TBA condensation indicates the extent of lipid peroxidation.

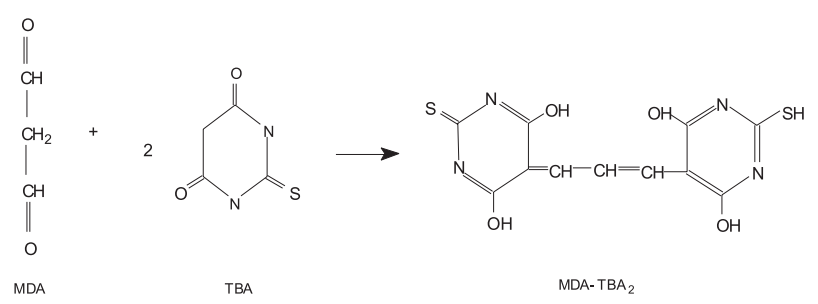

Figure 2. Reaction between MDA and TBA to form the MDA-TBA2 pigment

The reaction velocity depends of the temperature, $\mathrm{pH}$ and concentration of TBA. The maximum intensity of the pigment is obtained in $60 \mathrm{~min}$ in boiling water bath $;^{20}$ the reaction rate is faster in acid conditions, ${ }^{62}$ and when the concentration of TBA solution increased from 20 to $80 \mathrm{mM}$, the reaction time decreased from $30 \mathrm{~min}$ to approximately 5 min. ${ }^{66}$

Although this is an easy and inexpensive method, the use of TBARS test has received wide criticism over the years. The main problem is the lack of sensitivity and specificity, since TBA reacts with a variety of compounds such as sugars, amino acids, bilirubin and albumin, producing interference in colorimetric and fluorimetric MDA measurement. Therefore, TBARS test cannot be considered 
representative of oxidative stress, once it is unspecific for lipid peroxidation, because other aldehydes and non-lipids materials present in biological samples may also form TBA adducts. ${ }^{64}$

One of these interferences is the presence of a yellow chromagen ( $\max 450-460 \mathrm{~nm}$ ) formed by a variety of aldehydic compounds reacting with TBA and overlapping the pink peak of the MDA-TBA ${ }_{2} \cdot{ }^{21,64}$ Other interference is a product of sucrose pyrolysis, that reacts with TBA to form a pink chromogen absorbing at $532 \mathrm{~nm}$, which is formed in total absence of lipid peroxidation. ${ }^{64}$ In addition, MDA is not exclusively produced by polyunsaturated fatty acids. Radiation and iron-dependent damage to amino acids, carbohydrates, peptides, proteins and nucleic acids can also release intermediates which form an MDA-TBA adduct. ${ }^{22,67}$

Proteins consist in a problematical aspect once albumin, for instance, interacts with MDA-TBA adducts and this interaction may lead to an inappropriate and strong increase in natural MDA-TBA fluorescence, overestimating the authentic result in fluorimetric assay. ${ }^{46}$ TBA derivatization procedure itself leads to the formation of several unrelated fluorescent species showing the low specificity of this technique. ${ }^{60}$ Thus, the wide reactivity of TBA with other substances makes this technique non-specific and inappropriate for measurement of MDA, producing a false overestimated result of lipid peroxidation.

Furthermore, an additional important limitation is that MDA is unstable for a long period of time, because its oxidation yields organic alcohols and acid, not determined by the TBARS test. ${ }^{20,68,69}$

Thus, it could be supposed that the use of colorimetric or fluorimetric techniques may give mistaken results, particularly in situations such as initial stages of human diseases, where lipid peroxidation can be smaller when compared to the non-specific background reaction between TBA and products not derived from lipid peroxidation. ${ }^{53}$

\section{Chromatography assay}

The HPLC assay normally utilize a pre-treatment as derivatization to enhance the sensitivity of an analysis by incorporating groups into a derivative detectable at higher sensitivities, or are more lipophilic and thus more readily extracted or exhibit superior chromatographic properties. Therefore, the need for a more specific, reliable and reproducible technique for measurement of MDA has prompted modifications of currently available methods.

Bird et al. ${ }^{15}$ described high performance liquid chromatographic (HPLC) techniques for determining MDA. HPLC assay for MDA is a useful method to measure lipid peroxidation, since there is separation of the MDA-TBA ${ }_{2}$ adduct from other interfering compounds by reverse phase HPLC techniques. Several researches have adapted these HPLC techniques ${ }^{47,49,50,56}$ so that the procedure offers some advantages in terms of specificity, recovery and reproducibility.
The initial analytical procedure to sample treatment is basically the same from TBA test. Some steps, though, can be added to improve the method. Extraction of the sample with n-butanol before its injection into chromatographer ${ }^{56,70}$ is one of these, which avoid interference formation and extend the lifetime of the column by removing contaminants from incubation mixture.

Some researches discuss the difference between detection of free and total plasma MDA. ${ }^{70}$ Free MDA is unbound to proteins while total MDA is bound. Only low amounts of free MDA are present in biological samples, and alkaline hydrolysis step with $\mathrm{NaOH}$ is necessary to obtain a more complete and uniformed release of proteinbound MDA, ${ }^{51,56}$ resulting in a higher MDA value, once total MDA is being considered.

The detectors more used are visible at 532 or $535 \mathrm{~nm}^{28,49,50,56}$ and fluorescent. ${ }^{56,60,70}$ There was a research that carried out MDA determination with a UV absorbance detector. ${ }^{52}$ The Table 1 shows methodologies with the different detectors, presenting some MDA levels in different samples. It is possible to notice that there is no agreement among the techniques. The retention time of the methods evaluated in this review ranged from 1.8 to $7.0 \mathrm{~min}$ and the reference levels ranged from $0.2 \times 10^{-6}$ to $4.45 \mu \mathrm{M}$ of MDA.

Both visible and fluorescent detector are good at specificity and sensibility, and respect analytical performances, including baseline noise level, baseline drift, signal-to-noise ratio, sensitivity and specificity. ${ }^{15}$ On the other hand, observing the Table 1 , it is possible to verify the high sensibility of the fluorescent detector. Fukunaga et al. ${ }^{70}$ found the lowest plasma MDA reference levels with fluorescent detection compared with visible detection. However, if the biological samples did not receive a pre-treatment as deproteinization or extraction, the fluorescence of the MDA-TBA 2 complex can be increased in the presence of albumin, ${ }^{46}$ resulting in false increased of MDA.

In relation to UV detector, it becomes difficult to take a precise conclusion because there is only one research about it. Furthermore, the methodology offered in this work ${ }^{52}$ is based on direct MDA measurement and authors did not provide data about the MDA-TBA complex formation.

Mobile phase is, in the majority of studies, methanol: potassium phosphate buffer in concentrations from 10 to $50 \mathrm{mM} \cdot{ }^{49,50,52,56,60}$ Grotto et al. ${ }^{51}$ did an important modification in mobile phase, employing water instead of potassium phosphate buffer, preventing the damage of the chromatographic system. Fukunaga et al..$^{70}$ used acetonitrile: water.

Examination of research data clearly indicates that the MDA quantification by visible or fluorescent spectrophotometry methods is higher than MDA levels obtained from HPLC techniques. These results are certainly related to the fact that specrophotometric techniques are not as specific as the HPLC techniques. Thus, HPLC methods are more adequate for accurate detection of lipid peroxidation products.

Besides the HPLC methods, the MDA determination by gas chro-

Table 1. HPLC methods and their different reference levels (RL), recovery, retention time (RT), samples and detectors: fluorescent (F), ultraviolet (UV) and visible (VIS)

\begin{tabular}{lccccc}
\hline Method & $\mathrm{RL}^{\mathrm{a}} \mu \mathrm{M}$ & Recovery & RT $(\mathrm{min})$ & Sample & Ref. \\
\hline HPLC-F & 0.47 & $\mathrm{NS} *$ & 3.75 & Guinea pig plasma & 58 \\
HPLC- UV & 0.5 & $98.8 \%$ & 1.6 & Human serum & 52 \\
HPLC- VIS & 0.11 & $101 \%$ & 7.0 & Human plasma & 50 \\
HPLC-F & $0.2 \times 10^{-6}$ & $\mathrm{NS}$ & 2.0 & Rat plasma & 68 \\
HLPC - UV & 2.16 & $93.6 \%$ & 7.0 & Human plasma & 59 \\
HPLC - VIS & 4.45 & $99.1 \%$ & 1.85 & Human plasma & 51 \\
\hline
\end{tabular}

* NS $=$ not specified. Reference level ${ }^{\mathrm{a}}=$ this value means the healthy subjects levels found obtained in the specific work that resulted in referent manuscript. HPLC-UV ${ }^{\mathrm{b}}=$ in this method, direct MDA was measured, without TBA derivatization. HPLC-UV ${ }^{\mathrm{c}}=$ in this method it was used 2, 4-dinitrophenylhydrazine as derivative 
matography $(\mathrm{CG})$ is a technique that has been widely used in the last years. Since the MDA-TBA methodologies require extremely difficult sample preparation processes, such as low $\mathrm{pH}$ and high temperatures, and normally more sample are required.

On the other hand, CG methodologies need previous derivatization, but did not require vigorous conditions or much sample volume. Some of the main derivatives proposed are 2,3-propanediol, ${ }^{72}$ 2-hydrazino-benzothiazole ${ }^{73}$ and pentafluoro-phenylhydrazine. ${ }^{74}$ Depending on the method, either free or bound MDA may be determined and aldehydes other than MDA can be identified. In addition, headspace solid-phase micro extraction (HS-SPME) has been used for the analyses of volatile aldehydes in biological matrices, and in a recent study carried out by Fujioka and Shibamoto, ${ }^{75}$ the HS-SPME was applied to prepare samples for MDA analyses, improving the sample preparation steps in lipid peroxidation researches. The disadvantage of this methodology is the high cost of the apparatus and the need of a qualified person to manipulate the apparatus. Thus, there was no time-consuming and no need of extensive biological sample preparation, on the other hand sophisticated equipment is necessary, which is not readily available to ordinary laboratories.

\section{CONCLUSION}

Estimating the extent of lipid peroxidation, it has a high significance in pathologies and in toxicology associated with oxidative stress. MDA is a good biomarker, but the most common methods to MDA detection, TBARS reaction by spectrophotometer or fluorescent detection, are insufficiently sensitive and specific. TBA can react with several cellular constituents other than those derived from lipid peroxidation and less specifically with MDA. Fortunately, with fast development in analytical techniques, TBARS assay can be used in association with other indices of lipid peroxidation, such as 4-hydroxynnenal, conjugated dienes, ethane and pentane gases, and isoprostanes. Unluckily, these methods have limitations because they are either too expensive, too time consuming or their application needs specialized personnel. Therefore, chromatography techniques are the preferred methods to determine the true amount of MDA in biological materials, once they are reliable and specific, without the presence of artifacts or methodological pitfalls. Thus, this separation technique helps in a more precise determination of how oxidative injury derived from lipid peroxidation participates in the pathogenesis of many diseases that afflict millions of human subjects as well as the toxicological effects of pollutants such as metals, solvents and xenobiotics in humans and animals. Comparing CG and HPLC methodologies, both are also reliable and specific, but CG, even needing a small sample, are more expensive than HPLC methodologies and the equipment is considered more sophisticated and is not frequently available in laboratories. HPLC UV-VIS is widely used in clinical laboratory and there are methodologies utilizing little sample-consuming with total reliability and specificity.

\section{ACKNOWLEDGEMENTS}

The authors would like to thank DAAD (Deutscher Akademischer Austauschdienst), Wissenschaftliche Gerätebau Dr. Ing. H. Knauer $\mathrm{GmbH}$ for HPLC apparatus support and to CNPq for providing fellowships. S.C. Garcia is recipient from a CNPq Research Fellowship.

\section{REFERENCES}

1. Urso, M .L.; Clarkson, P. M.; Toxicology 2003, 189, 41

2. Gillham, B.; Papachristodoulou, D. K.; Thomas, J. H.; Will's: Biochemical basis of medicine, $3^{\text {rd }}$ ed., Butterworth- Heinemann: Oxford, 1997.
3. Kesavulu, M. M.; Rao, B. K.; Giri, R.; Vijaya, J.; Subramanyam, G.; Apparao, C.; Diabetes Res. Clin. Pract. 2001, 53, 33.

4. Cerutti, P. A.; Lancet 1994, 344, 862.

5. Halliwell, B.; Br. Med. J. 1993, 307, 885.

6. Halliwell, B.; Chirico, S.; Am. J. Clin. Nutri. 1993, 57, 715.

7. Seto, H.; Akiyama, K.; Okuda, T.; Hashimoto, T.; Takesue, T.; Ikemura, T.; Chem. Lett. 1981, 52, 707.

8. Esterbauer, H.; Cheeseman, K. H.; Methods Enzymol. 1990, 186, 407.

9. Esterbauer, H.; Schaur, R. J.; Zollner, H.; Free Radical Biol. Med. 1991, 11,81 .

10. Dormandy, T. L.; Wickens, D. G.; Chem. Phys. Lipids 1987, 45, 356.

11. Frank, H.; Hintze, T.; Bimboes, D.; Remmer, H.; Toxicol. Appl. Pharmacol. 1980, 56, 337.

12. Morrow, J. D.; Frei, B.; Longmire, A. W.; Gaziano, J. M.; Lynch, S. M.; Shyr, Y.; Strauss, W. E.; Oates, J. A.; Roberts, L. J.; New Engl. J. Med. 1995, 332, 1198.

13. Levine, R. L.; Williams, J. A.; Stadtman, E. R.; Shacter, E.; Methods Enzymol. 1994, 233, 346.

14. Bird, R. P.; Hung, S. S. O.; Hadley, M.; Draper, H. H.; Anal. Biochem. 1983, $128,240$.

15. Ichinose, T.; Miller, M. G.; Shibamoto, T.; Lipids 1989, 24, 895.

16. Rosenblum, E. R.; Gavaler, J. S.; Van Thiel, D. H.; Free Radical Biol. Med. 1989, 7, 569.

17. Dahle, L. K.; Hill, E. G.; Holman, R. T.; Arch. Biochem. Biophys. 1962, 98, 253.

18. Alessio, H. M. In Handbook of Oxidants and Antioxidants in Exercise; Hanninen, O.; Packer, L.; Sen, C. K., eds.; Elsevier: Amsterdam, 2000.

19. Pryor, W. A.; Stanley, J.; Blair, E.; Lipids 1976, 11, 370.

20. Tarladgis, B. G.; Watts, B. M.; J. Am. Oil Chem. Soc. 1960, 37, 403.

21. Sinnhuber, R. O.; Yu, T. C.; J. Jpn. Oil Chem. Soc. 1977, 26, 259.

22. Bird, R. P.; Draper, H. H.; Methods Enzymol. 1984, 105, 299.

23. Shaw, C. A.; Taylor, E. L.; Megson, I. L.; Rossi, A. G.; Mem. Inst. Oswaldo Cruz 2005, 100, 67.

24. Joosten, E.; Clin. Chem. Lab. Med. 2001, 39, 717.

25. Singer, B.; Kusmierek, J. T.; Annu. Rev. Biochem. 1982, 51, 655.

26. Parsons, R.; Li, G. M.; Longley, M. J.; Fang, W. H.; Papadopoulos, N.; Jen, J.; de la Chapelle, A.; Kinzler, K. W.; Vogelstein, B.; Modrich, P.; Cell 1993, 75, 1227.

27. Lee, Y. S.; Wurster, R. D.; Cancer Lett. 1994, 1, 19.

28. Cirak, B.; Inci, S.; Palaoglu, S.; Bertan, V.; Clin. Chim. Acta 2003, 327, 103.

29. Wolff, S. P.; Dean, R. T.; Biochem. J. 1987, 245, 243.

30. Scott, B.; Deman, A.; Peeters, P.; Van den Branden, C.; Stolear, J. C.; Van Camp, G.; Verbrrlen, D.; Nephrol. Dial. Transplant. 2003, 18, 737.

31. Coyle, J. T.; Puttfarcken, P.; Science 1993, 262, 689.

32. Marchasson, I. B.; Beauvieux, M. C. D.; Peuchant, E.; Harston, S. R.; Decamps, A.; Reignier, B.; Emeriau, J. P.; Rainfray, M.; Age Ageing 2001, 30, 235.

33. Sato, N.; Fujii, K.; Yuge, O.; Morio, M.; J. Appl. Toxicol. 1992, 12, 365 .

34. De Zuart, L. L.; Meerman, J. H. N.; Commandeur, J. N. M.; Vermeulen, N. P. E.; Free Radical Biol. Med. 1999, 26, 202.

35. Gupta, R. S.; Gupta, E. S.; Dhakal, B. K.; Thakur, A. R.; Ahnn, J.; Mol. Cells 2003, 17, 132.

36. Abd-Elghaffar, S. K.; El-Sokkary, G. H.; Sharkawy, A. A.; Neuro. Endocrinol. Lett. 2005, 26, 609.

37. Sidorov, V. S.; Nomova, N. N.; Vysotskaia, R. U.; Feklov, I. A.; Prikl. Biokhim. Mokrobiol. 2002, 38, 345.

38. Poot, M.; Verkerk, A.; Koster, J. F.; Esterbauer, H.; Jongkind, J. F.; Mech. Ageing Dev. 1988, 43, 1.

39. Corongiu, F. P.; Poli, G.; Dianzani, M. U.; Chem. Biol. Interact. 1986, $59,147$. 
40. Mendis, S.; Sobotka, P. A.; Euler, D. E.; Clin. Chem. 1994, 40, 1485.

41. Allerheiligen, S. R. B.; Ludden, T. M.; Drug Metab. Dispos. 1987, 15, 794.

42. Lawson, J. A.; Rokach, J.; FitzGerald, G. A.; J. Biol. Chem. 1999, 274, 24441.

43. Roberts, L. J.; Morrow, J. D.; Ann. NY Acad. Sci. 1994, 744, 237.

44. Han, D.; Loukianoff, S.; McLaughlin, L. In ref. 18.

45. Slatter, D. A.; Bolton, C. H.; Bailey, A. I.; Diabetologia 2000, 43, 550

46. Del Rio, D.; Pellegrini, N.; Colombi, B.; Bianchi, M.; Serafíni, M.; Torta, F.; Tegoni, M.; Musci, M.; Brighenti, F.; Clin. Chem. 2003, 49, 690.

47. Lepage, G.; Munoz, G.; Champagne, J.; Roy, C. C.; Anal. Biochem. 1991, 197, 277.

48. Liu, J.; Yeo, H. C.; Doniger, S. J.; Ames, B. N.; Anal. Biochem. 1997, 245,161 .

49. Nielsen, F.; Mikkelsen, B. B.; Nielsen, J. B.; Andersen, H. R.; Grandjean, P.; Clin. Chem. 1997, 43, 1209.

50. Templar. J.; Kon, S. P.; Milligan, T. P.; Newman, D. J.; Raftery, M. J.; Transplantation 1999, 14, 946.

51. Grotto, D.; Santa Maria, L. D.; Boeira, S.; Valentini, J.; Charão, M. F.; Moro, A. M.; Pomblum, V. J.; Nascimento P. C.; Garcia, S. C.; J. Pharm. Biomed. Anal. 2007, 43, 619 .

52. Karatas, F.; Karatepe, M.; Baysar, A.; Anal. Biochem. 2002, 311, 76.

53. Folmer, V.; Santos, F. W.; Savegnago, L.; Brito, V. B.; Nogueira, C. V.; Rocha, J. B.; Toxicol. Lett. 2004, 153, 333.

54. Draper, H. H.; Csallany, A. S.; Hadley, M.; Free Radical Biol. Med. 2000, 29, 1071.

55. Oter, S.; Korkmaz, A.; Topal, T.; Ozcan, O.; Sadir, S.; Ozler, M.; Ogur,
R.; Bilgic, H.; Clin. Biochem. 2005, 38, 706.

56. Hong, Y.; Yeh, S.; Chang, C.; Hu, M.; Clin. Biochem. 2000, 33, 619.

57. Wong, S. H. Y.; Knight, J. A.; Hopfer, S. M.; Zaharia, O.; Leach, C. N.; Sunderman, F. W.; Clin. Chem. 1987, 33, 214.

58. Tamura, H.; Kitta, K.; Shibamoto, T.; J. Agric. Food Chem. 1991, 39, 439.

59. Gonçalves, T. L.; Erthal, F.; Corte, C. L. D.; Muller, L. G.; Piovezan, C.

M.; Nogueira, C. W.; Rocha, J. B. T.; Clin. Biochem. 2005, 38, 1071.

60. Lykkesfeldt, J.; Clin. Chem. 2001, 47, 1725.

61. Pilz, J.; Meineke, I.; Gleiter, H. C.; J. Chromatogr., B: Anal. Technol. Biomed. Life Sci. 2000, 742, 315.

62. Ohkawa, H.; Ohishi, N.; Anal. Biochem. 1979, 95, 351.

63. Yagi, K.; Nishigaki, I.; Ohama, H.; Vitamins 1968, 37, 105.

64. Knight, J. A.; Pieper, R. K.; Mc Clellan, L.; Clin. Chem. 1988, 34, 2433.

65. Janero, D. R.; Free Radical Biol. Med. 1990, 9, 515.

66. Raharjo, S.; Sofos, J. N.; Schmidt, G. R.; J. Agric. Food Chem. 1992, 40, 2182.

67. Duran, L.; Tappel, A. L.; Radiat. Res. 1958, 9, 498.

68. Almandos, M. E.; Giannini, D. H.; Ciarlo, A. S.; Boery, R. L.; J. Sci. Food Agric. 1986, 37, 54.

69. Seo, C. W.; J. Food Sci. 1976, 41, 594.

70. Fukunaga, K.; Takama, K.; Suzuki, T.; Anal. Biochem. 1995, 230, 20.

71. Lee, S. H.; Csallany, A. S.; Lipids 1987, 22, 104.

72. Lakshminarayana, G.; Cornwell, D. G.; Lipids 1986, 21, 175.

73. Beljean-Leymarie, M.; Bruna, E.; Anal, Biochem. 1988, 173, 174.

74. Tomita, M.; Okuyama, T.; Hatta, Y.; Kawai, S.; J. Chromatogr. 1990, $526,174$.

75. Fujioka, K.; Shibamoto, T.; J. Agric. Food Chem. 2005, 53, 4708. 